\title{
A pregnancy detection assay using milk samples: Evaluation and considerations
}

\author{
Bradley C. Lawson, ${ }^{*}$ Abid Hussain Shahzad, ${ }^{*}$ Karmella A. Dolecheck, ${ }^{*}$ Edmond L. Martel, $\dagger$ \\ Katherine A. Velek, $†$ Denise L. Ray, ${ }^{*}$ John C. Lawrence,† and William J. Silvia*1 \\ *Department of Animal and Food Sciences, University of Kentucky, Lexington 40546-0215 \\ †ldexx Laboratories Inc., Westbrook, ME 04092
}

\begin{abstract}
Two experiments were conducted to evaluate a pregnancy-detection assay based on the measurement of pregnancy-associated glycoproteins (PAG) in milk samples. In experiment 1 , milk samples were collected on the day of first pregnancy check $(33-52 \mathrm{~d}$ postinsemination; $\mathrm{n}=119)$ or second check $(60-74 \mathrm{~d}$ postinsemination; $\mathrm{n}=60$ ). The accuracy in identification of pregnant and nonpregnant cows was $99 \%$ at first check. Only $6 \%$ of samples were found to be within an intermediate range of PAG concentrations and classified as requiring recheck by the assay. At second check, the accuracy of the assay was $98 \%$. Fifteen percent of these samples were classified as requiring recheck. In experiments $2 \mathrm{a}(\mathrm{n}=17$ cows $)$ and $2 \mathrm{~b}(\mathrm{n}=16$ cows $)$, milk and plasma samples were collected from cows at weekly intervals beginning 2 (experiment $2 \mathrm{a}$ ) or $4 \mathrm{~d}$ (experiment $2 \mathrm{~b}$ ) after insemination. The earliest time point at which pregnant cows were accurately classified as pregnant by the assay was on d 30 postinsemination. A transient decline in PAG levels into the intermediate range was observed on d 46 to 72 postinsemination. This coincides with the time of recheck in experiment 1. Results obtained with the plasma samples were essentially the same. The accuracy of pregnancy identification based on milk samples from nonpregnant and pregnant cows was 99\%. Levels of PAG in milk were useful in identifying 6 incidences of embryonic mortality. No consistent relationship was noted between the timing of the decline in PAG levels and the timing of luteal regression in this small number of cows.
\end{abstract}

Key words: pregnancy, milk, accuracy

\section{INTRODUCTION}

Early diagnosis of pregnancy is an important part of any effective reproductive management plan for

Received April 14, 2014.

Accepted June 25, 2014

${ }^{1}$ Corresponding author: wsilvia@uky.edu modern dairy farms. On most farms, early diagnosis of pregnancy is done by a skilled veterinarian, either by transrectal palpation or ultrasonography of the uterus. Pregnancy diagnosis can be a problem for dairy farmers in areas where veterinary support is limited. An alternative approach is to use a pregnancy detection assay. In the 1980s, several companies marketed onfarm, milk progesterone tests (Nebel, 1988; Nebel et al., 1989; Romagnolo and Nebel, 1993). They offered the dairy worker the convenience of collecting milk samples and immediate results. However, progesterone is an indirect indicator of pregnancy status. Cows can have high concentrations of progesterone for reasons other than pregnancy. For that reason, the technology was very effective at identifying nonpregnant cows (>90\% accuracy), but less so for pregnant cows $(<80 \%$ accuracy, Nebel, 1988). Adoption of this technology was too low to remain economically viable. In 2002, a pregnancy-detection assay based on the measurement of pregnancy-associated glycoproteins (PAG) became available to dairy farmers (BioPRYN, BioTracking LLC, Moscow, ID). The assay is limited to serum or plasma samples and must be sent to a laboratory for analysis. Turnaround time is usually 2 to $3 \mathrm{~d}$, depending on the laboratory. Since then, other companies have marketed similar services either directly or through commercial laboratories. The PAG are synthesized and secreted by placental tissue, and therefore are direct indicators of pregnancy (Telugu et al., 2009). These assays are accurate at identifying both pregnant and nonpregnant cows at $27 \mathrm{~d}$ postinsemination or later (>90\% accuracy; Sasser et al., 1986; Humblot et al., 1988; Zoli et al., 1992; Patel et al., 1995; Green et al., 2005; Silva et al., 2007). Though successful, the application of this technology has been limited by the requirement for collecting blood samples. Recently, Idexx Laboratories Inc. (Westbrook, ME) has developed a pregnancy-detection assay based on measurement of PAG in milk. Preliminary reports on the validity of PAG-based pregnancy-detection assays using milk samples, including the Idexx Laboratories assay, have been positive (Leblanc, 2013; Gajewski etal., 2014). 
The objectives of the 3 experiments reported herein were to (1) determine the accuracy of this milk-based pregnancy-detection assay, (2) determine the optimum time for early pregnancy detection using this assay, and (3) to compare the results of the milk-based assay to those obtained with the established plasma-based assay.

\section{MATERIALS AND METHODS}

\section{Experiment 1}

This experiment was designed to assess the accuracy of the milk-based pregnancy detection assay. Composite milk samples $(35 \mathrm{~mL}, \mathrm{n}=179)$ were collected from cows on a commercial dairy farm on the day of pregnancy determination by ultrasonography. These samples were collected at first pregnancy check (33-52 $\mathrm{d}$ after insemination; $\mathrm{n}=119)$ or at recheck $(60-74 \mathrm{~d}$ after insemination; $\mathrm{n}=60$ ). Milk samples were collected into 40-mL polypropylene, conical centrifuge tubes containing 1 drop (approximately $50 \mu \mathrm{L}$ ) of 2-bromo-2 nitropropane-1, 3-diol (18\% solution, Bronolab W II, D\&F Control Systems Inc., Dublin, CA) as a preservative. Samples were stored refrigerated for up to $4 \mathrm{wk}$, then shipped by overnight delivery to Idexx Laboratories Inc. for analysis. Relative levels of PAG were determined using an ELISA procedure now available to commercial laboratories, veterinarians, and so on from the manufacturer in kit form. The kit is not designed to be quantitative. Two reference samples, 1 low (not pregnant) and 1 high (pregnant), are run in each assay for accuracy assessment and quality control. Samples are classified as not pregnant, pregnant, or requiring recheck relative to predetermined optical density thresholds. Optical density readings (adjusted for background) were reported to us as an indication of the relative level of PAG in the sample. Idexx personnel were not informed of pregnancy status until after the optical density data were reported to us. The ability of the ELISA to determine the pregnancy status of cows was evaluated by calculating the following 5 parameters as defined by Silva et al. (2007): (1) negative predictive value, the percent of samples identified by the assay as nonpregnant that were from confirmed nonpregnant cows; (2) positive predictive value, the percent of samples identified by the assay as pregnant that were from confirmed pregnant cows; (3) specificity, the percent of samples from confirmed nonpregnant cows identified by the assay as nonpregnant (samples classified as requiring recheck not included); (4) sensitivity, the percent of samples from confirmed pregnant cows identified by the assay as pregnant (samples classified as requiring recheck not included); and (5) accuracy, the percent of samples from confirmed nonpregnant and pregnant cows accurately identified as pregnant or nonpregnant by the assay (samples classified as requiring recheck not included). The agreement between pregnancy diagnosis by ultrasonography and the assay was determined by calculating the kappa $(\kappa)$ statistic using the FREQ procedure of SAS (1985). Kappa greater than 0.80 is considered to indicate a high degree of agreement (Watson and Petrie, 2010).

\section{Experiment 2a}

This experiment had 3 objectives: (1) to assess the accuracy of the milk-based pregnancy-detection assay, (2) to more precisely determine the earliest time point at which pregnancy can be accurately determined using the milk-based pregnancy-detection assay, and (3) to compare the results obtained with the milk-based assay to results using the previously validated plasma- or serum-based pregnancy detection assay. Holstein cows $(\mathrm{n}=17)$ from the University of Kentucky Coldstream Dairy Research herd (Lexington) were bred using timed AI according to the timeline shown in Figure 1. The synchronization protocol consisted of Ovsynch (Pursley et al., 1995; Wiltbank and Pursley, 2014). The first injection of $\mathrm{GnRH}$ in the Ovsynch program (d -10 on Figure 1) was preceded by injections of GnRH and $\mathrm{PGF}_{2 \alpha} 7$ and $9 \mathrm{~d}$ earlier, respectively. This is commonly referred to as G7G (Wiltbank and Pursley, 2014), a modification of the G6G presynchronization protocol developed by Bello et al. (2006). Fifteen cows were 46 to $91 \mathrm{~d}$ postpartum at the start of the synchronization protocol; therefore, they were 65 to $110 \mathrm{~d}$ postpartum when inseminated. This was the first insemination postpartum. The other 2 cows were 242 and $286 \mathrm{~d}$ postpartum at the start of the synchronization protocol. These cows had been inseminated at least once before this synchronization or timed insemination. The day of insemination was designated $\mathrm{d} 0$ of the experiment. Starting on d 2 after insemination, the cows were sampled at 7-d intervals. Pregnancy was determined by transrectal ultrasonography at $37 \mathrm{~d}$ after insemination, then confirmed at 65 and $93 \mathrm{~d}$ after insemination. Sampling continued through d 58 after insemination if the cow was not pregnant via ultrasonography on $\mathrm{d} 37$. Sampling continued through d 93 if the cow was found pregnant on $d$ 37. On the days of sampling, a composite milk sample $(35 \mathrm{~mL})$ was collected as described for experiment 1. Samples were stored refrigerated for up to $3 \mathrm{wk}$, then shipped overnight to the Idexx Laboratories Inc. for PAG determination. After milking, a blood sample $(10 \mathrm{~mL})$ was collected from the tail vein by 
venipuncture into evacuated tubes containing EDTA as anticoagulant (Vacutainer, Becton, Dickinson and Co., Franklin Lakes, NJ). Blood samples were centrifuged for $20 \min \left(1,500 \times g\right.$ at $\left.20^{\circ} \mathrm{C}\right)$ so that plasma and cellular components could be separated. After centrifugation, plasma was transferred to two 7 -mL plastic storage vials and stored at $-20^{\circ} \mathrm{C}$. One vial was shipped with the milk samples to Idexx for PAG determination. The other vial was used for quantification of progesterone using a solid-phase, radioimmunoassay kit (Coat-aCount Progesterone, Diagnostic Products Corporation, Los Angeles, CA) as previously described (Patterson et al., 1995). At Idexx, levels of PAG in plasma and milk samples were determined using their ELISA kit procedures. Both the plasma- and milk-based assays are designed to be qualitative, classifying the results as pregnant, not pregnant, or requiring recheck. The Idexx technicians reported both the qualitative assessment and the optical density (OD; adjusted for background) measurements to us. The pregnancy status of animals was not disclosed to the Idexx laboratory personnel until after the OD and pregnancy status data were reported to us. Cows were maintained with the rest of the milking herd and observed for expression of estrous behavior for the duration of the experiment.
Animals were assigned to physiological status groups retrospectively, based on concentrations of progesterone, relative level of PAG, expression of estrus, and uterine ultrasonography. The groups were (1) nonpregnant-normal cycle, (2) nonpregnant-long cycle, (3) pregnant, and (4) embryonic mortality. The nonpregnant-normal cycle group had a concentration of progesterone below $1 \mathrm{ng} / \mathrm{mL}$ on d 2, greater than $1 \mathrm{ng} /$ $\mathrm{mL}$ on $\mathrm{d} 9$ and 16 , and less than $1 \mathrm{ng} / \mathrm{mL}$ on $\mathrm{d} 23$. The category nonpregnant-long cycle had a concentration of progesterone below $1 \mathrm{ng} / \mathrm{mL}$ on d 2, greater than $1 \mathrm{ng} / \mathrm{mL}$ on $\mathrm{d} 9,16$, and 23 , and less than $1 \mathrm{ng} / \mathrm{mL}$ on $\mathrm{d} 30$. The category pregnant included animals that were confirmed pregnant by ultrasonography on d 37, 65, and 93 after insemination. The category embryonic mortality included animals that had a relative level of PAG in milk that exceeded the typical nonpregnant baseline $(\mathrm{OD}=>0.02$; baseline mean $=6 \mathrm{SEM})$ for at least 2 consecutive weeks beginning sometime within the period from d 23 through 37 postinsemination. These animals also maintained concentrations of progesterone greater than $1 \mathrm{ng} / \mathrm{mL}$ through at least $30 \mathrm{~d}$ postinsemination. The relative levels of milk PAG in the 2 nonpregnant groups (combined for analysis) were compared with the pregnant group on each sampling

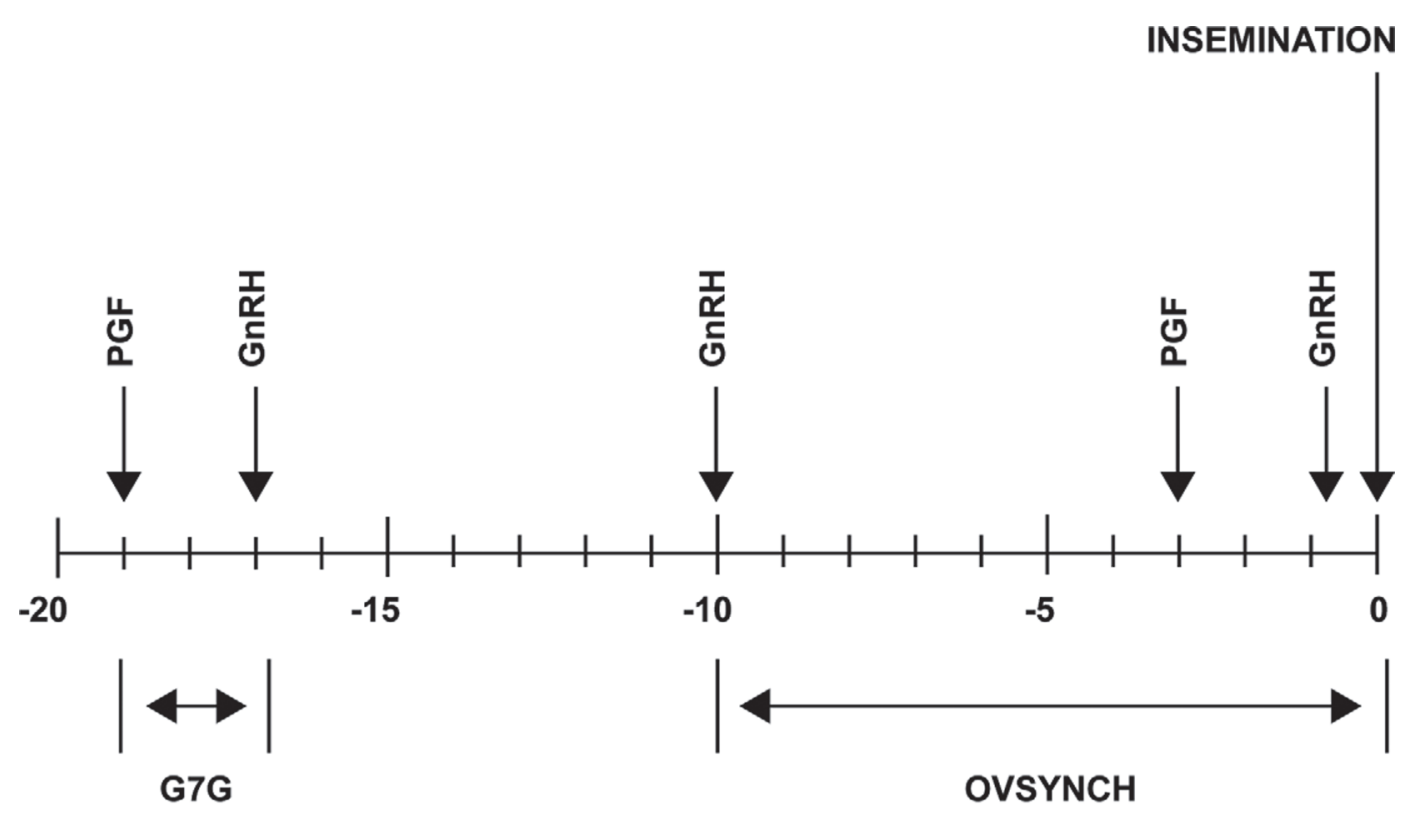

DAY PRIOR TO INSEMINATION

Figure 1. Timeline for the administration of hormone injections for the timed insemination protocol. The day of insemination was designated as d 0. PGF = Lutalyse Sterile Solution (Pfizer Inc., New York, NY), 25 mg, i.m; GnRH = Factrel (Fort Dodge Animal Health, Ft. Dodge, IA), $100 \mu \mathrm{g}$, i.m. G7G = protocol in which the first injection of $\mathrm{GnRH}$ in the Ovsynch program (d -10$)$ is preceded by injections of GnRH and $\mathrm{PGF}_{2 \alpha} 7$ and $9 \mathrm{~d}$ earlier, respectively. 
day to determine the earliest day on which PAG were greater in pregnant than nonpregnant animals. This comparison was done using the GLM procedure of SAS (1985).

\section{Experiment 2b}

The design was essentially the same as for Experiment 2a. Cows $(n=16)$ were 40 to $110 \mathrm{~d}$ postpartum at the start of the synchronization protocol so they were 59 to 129 d postpartum when inseminated. This was the first insemination postpartum for all of these cows. The only difference in design was that the first milk and plasma samples were collected on d 4 after insemination. Samples were then collected at 7 -d intervals thereafter, through d 60 postinsemination if not pregnant and d 95 postinsemination if pregnant. Pregnancy was determined by ultrasonography at 32 , 60 , and 95 d postinsemination. Statistical analyses were the same as described for experiment $2 \mathrm{a}$.

Additional analyses were conducted using the combined data from experiments $2 \mathrm{a}$ and $2 \mathrm{~b}$. The ability of the milk PAG ELISA to determine the pregnancy status of cows was evaluated by calculating the 5 parameters and the kappa statistic as described for experiment 1. The samples used for this analysis were those collected on d 30 or later from the cows in the 2 nonpregnant groups versus those collected at the same time points from cows in the pregnant group. The relationship between milk and plasma levels of PAG was determined using samples collected from pregnant cows and cows that experienced embryonic mortality $(\mathrm{n}=180$ samples). The relationship was evaluated using the CORR and REG procedures of SAS (1985). The baseline level of PAG was determined by calculating the mean OD for the first 3 samples (d 2 to 18 postinsemination) collected from all cows. All of the procedures described in this manuscript were reviewed and approved by the University of Kentucky Institutional Animal Care and Use Committee.

\section{RESULTS AND DISCUSSION}

Experiment 1 was conducted to evaluate the accuracy of the milk-based pregnancy-detection assay. Of the 119 samples collected at the first pregnancy check (32-52 d postinsemination), 60 were from pregnant cows (Table 1 ). The negative and positive predictive values were 100 and $98.5 \%$, respectively. The sensitivity and specificity were 100 and $97.9 \%$, respectively (excludes samples classified as requiring recheck; Table 1). The overall accuracy was $99.1 \%(\kappa=0.98$; excludes samples classified as requiring recheck; Table 1). Only 7 of the 119 samples $(5.9 \%)$ were classified as requiring recheck. The majority of these were from pregnant cows (5 of 7; Table 1 ). Of the 60 samples collected at the second pregnancy check (60-74 d postinsemination), $92 \%$ (55/60) were from pregnant cows (Table 2). The negative and positive predictive values were 83.3 and $100 \%$, respectively. The negative predictive value is based on just 6 samples. The sensitivity and specificity were 97.8 and $100 \%$, respectively (Table 2). The overall accuracy of the assay was $98.0 \%(\kappa=0.90)$. It should be noted again that these calculations exclude samples classified as requiring recheck; a relatively large number of samples $(9 / 60 ; 15 \%)$ were classified as such, all of which were from pregnant cows. Based on these data, the accuracy of the milk-based pregnancy-detection assay was confirmed. These results are in agreement with those previously reported for the same assay (LeBlanc, 2013).

Experiments $2 \mathrm{a}$ and $2 \mathrm{~b}$ were conducted to identify the earliest time point at which the milk-based pregnancy-detection assay could reliably identify pregnant

Table 1. Measurements of accuracy of the pregnancy detection assay in experiment $1^{1}$

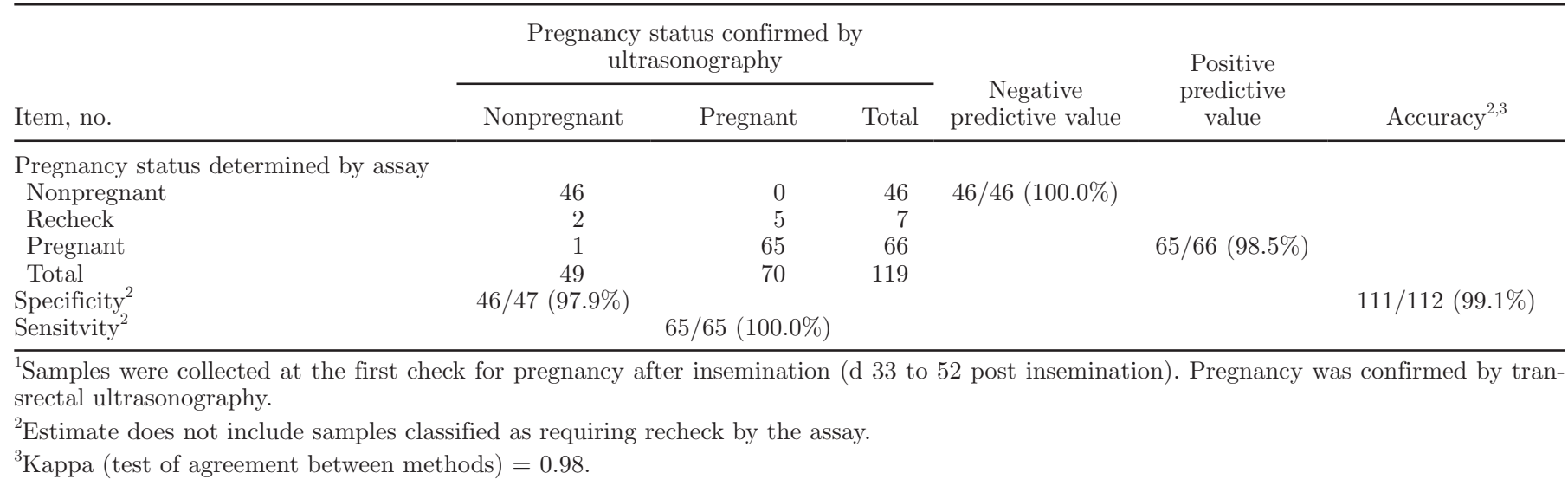


Table 2. Measurements of accuracy of the pregnancy detection assay in experiment $1^{1}$

\begin{tabular}{|c|c|c|c|c|c|c|}
\hline \multirow[b]{2}{*}{ Item, no. } & \multicolumn{3}{|c|}{$\begin{array}{c}\text { Pregnancy status confirmed by } \\
\text { ultrasonography }\end{array}$} & \multirow{2}{*}{$\begin{array}{l}\text { Negative } \\
\text { predictive } \\
\text { value }\end{array}$} & \multirow{2}{*}{$\begin{array}{l}\text { Positive } \\
\text { predictive } \\
\text { value }\end{array}$} & \multirow[b]{2}{*}{ Accuracy ${ }^{2,3}$} \\
\hline & Nonpregnant & Pregnant & Total & & & \\
\hline Nonpregnant & 5 & 1 & 6 & $5 / 6(83.3 \%)$ & \multirow[b]{3}{*}{$45 / 45(100.0 \%)$} & \\
\hline Recheck & 0 & 9 & 9 & & & \\
\hline Pregnant & 0 & 45 & 45 & & & \\
\hline
\end{tabular}

${ }^{1}$ Samples were collected at the second check for pregnancy after insemination (d 60 to 74 post insemination). Pregnancy was confirmed by transrectal ultrasonography.

${ }^{2}$ Estimate does not include samples classified as requiring recheck by the assay.

${ }^{3}$ Kappa (test of agreement between methods) $=0.90$.

cows. Samples were at or near basal levels, well below the requiring recheck threshold, in all samples collected on $\mathrm{d} 18$ or earlier. The average baseline level was OD $=0.000 \pm 0.003$ (mean \pm SEM). The earliest day on which the mean level of PAG in samples from pregnant cows were greater than those from nonpregnant cows was d 23 in experiment $2 \mathrm{a}$ and $\mathrm{d} 25$ in experiment $2 \mathrm{~b}$ $(P<0.004)$. None of the samples collected on $\mathrm{d} 23$ (experiment 2a) were classified as pregnant. Three of the 6 samples collected on d 23 (1 milk sample was spilled in transport) were classified as requiring recheck. The earliest milk sample to be classified as pregnant was collected on d 25 (experiment 2b) postinsemination (Table 3). Only 1 of the 6 samples collected at this time was classified as pregnant. Four samples were classified as requiring recheck. Thus, d 23 and 25 appear to be in a transition period when the levels of PAG in milk are beginning to rise. In most animals, concentrations of PAG have not increased enough to reach the pregnant threshold. By d 30 and 32, all pregnant cows were classified by the milk-based assay as pregnant. The temporal pattern of PAG levels in milk during the first $40 \mathrm{~d}$ after insemination appears similar to patterns reported in the blood (Sasser et al., 1986; Humblot et al., 1988; Zoli et al., 1992; Patel et al., 1995; Green et al., 2005, Thompson et al., 2010). In conclusion, the milk-based assay is accurate in identifying pregnant cows as early as d 30. Using a blood-based PAG assay, Silva et al. (2007) reported that pregnancy could be reliably detected on d 27 postinsemination.

Interestingly, $100 \%$ of the pregnant animals were classified as pregnant when sampled again on d 37, 39, and 44 . On d 46 (experiment 2b), 1 of the pregnant cows was classified as requiring recheck (Table 3 ). This begins a trend that continues through $\mathrm{d} 72$ in which 1 or more cows are thus classified. On d 74 and thereafter, all of the pregnant cows are classified as pregnant again. Thus, it appears that a transient decrease oc- curred in the level of PAG between d 46 and 72. This is very apparent when the actual OD readings from the milk-based assay are plotted (Figure 2). A similar pattern was observed through d 60 postinsemination by Thompson et al. (2010). This explains why a com-

Table 3. Assay classification of milk samples (nonpregnant, requiring recheck, pregnant), collected from pregnant cows sampled through the first $95 \mathrm{~d}$ of pregnancy in experiments $2 \mathrm{a}$ and $2 \mathrm{~b}$

\begin{tabular}{|c|c|c|c|}
\hline \multirow[b]{2}{*}{$\begin{array}{l}\text { Day } \\
\text { postinsemination }\end{array}$} & \multicolumn{3}{|c|}{ Assay classification, no. } \\
\hline & Nonpregnant & $\begin{array}{l}\text { Requiring } \\
\text { recheck }\end{array}$ & Pregnant \\
\hline \multicolumn{4}{|l|}{ Experiment 2a } \\
\hline 2 & 7 & 0 & 0 \\
\hline 9 & 7 & 0 & 0 \\
\hline 16 & 7 & 0 & 0 \\
\hline 23 & 3 & 3 & 0 \\
\hline 30 & 0 & 0 & 7 \\
\hline 37 & 0 & 0 & 7 \\
\hline 44 & 0 & 0 & 7 \\
\hline $51^{1}$ & 0 & 1 & 6 \\
\hline $58^{1}$ & 0 & 2 & 5 \\
\hline $65^{1}$ & 0 & 1 & 6 \\
\hline $72^{1}$ & 0 & 1 & 6 \\
\hline 79 & 0 & 0 & 7 \\
\hline 86 & 0 & 0 & 7 \\
\hline 93 & 0 & 0 & 7 \\
\hline \multicolumn{4}{|l|}{ Experiment $2 b$} \\
\hline 4 & 6 & 0 & 0 \\
\hline 11 & 6 & 0 & 0 \\
\hline 18 & 6 & 0 & 0 \\
\hline 25 & 1 & 4 & 1 \\
\hline 32 & 0 & 0 & 6 \\
\hline 39 & 0 & 0 & 6 \\
\hline $46^{1}$ & 0 & 1 & 5 \\
\hline $53^{1}$ & 1 & 1 & 4 \\
\hline $60^{1}$ & 0 & 1 & 5 \\
\hline $67^{1}$ & 0 & 1 & 5 \\
\hline 74 & 0 & 0 & 6 \\
\hline 81 & 0 & 0 & 6 \\
\hline 88 & 0 & 0 & 6 \\
\hline 95 & 0 & 0 & 6 \\
\hline
\end{tabular}

${ }^{1}$ Period of transient reduction in relative pregnancy-associated glycoprotein levels. 

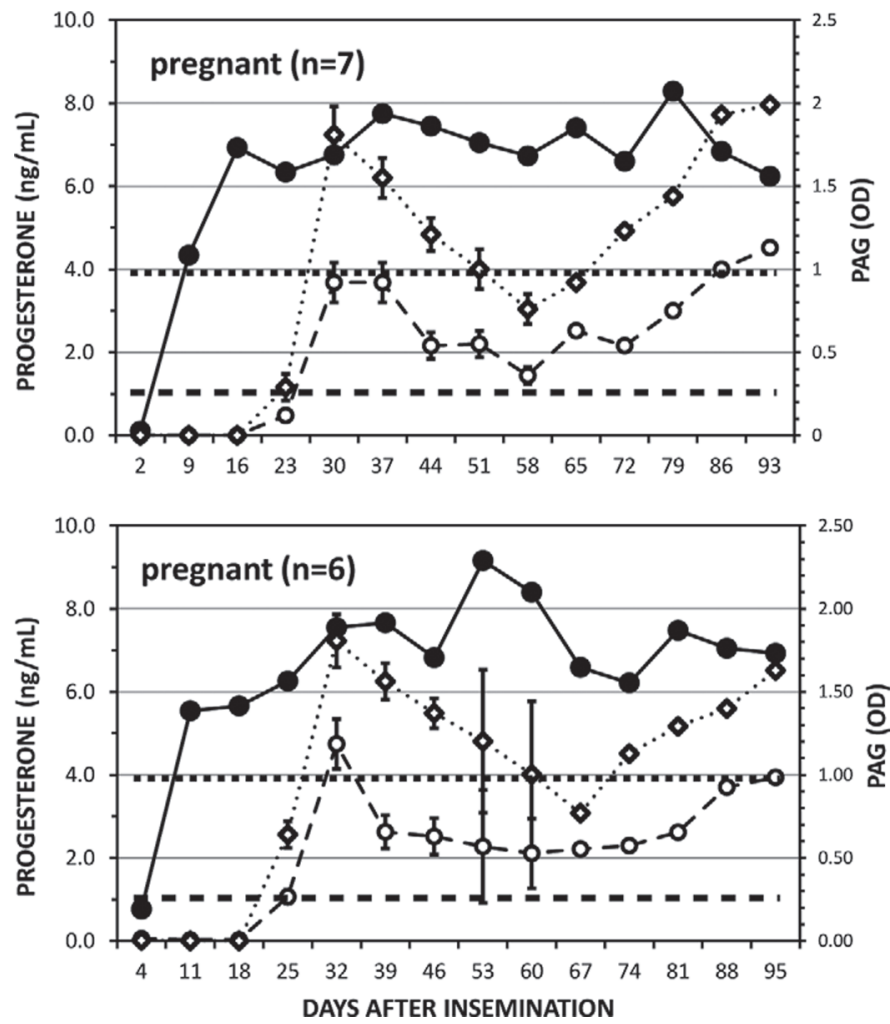

Figure 2. Relative levels of pregnancy-associated glycoproteins (PAG) in milk (open circles) and plasma (open diamonds) and concentrations of progesterone (solid circles) in plasma for pregnant cows in experiments $2 \mathrm{a}$ (top) and $2 \mathrm{~b}$ (bottom). Horizontal dotted line (optical density $=1.0$ ) is the threshold for classification as pregnant in the assay for plasma samples. Horizontal dashed line (optical density $=0.25$ ) is the threshold for classification as pregnant in the assay for milk samples. Vertical bars on milk and plasma PAG levels for the first 9 samples indicate SEM. These are included to facilitate comparison to milk and plasma PAG in nonpregnant cows in Figure 4.

paratively high percentage of samples collected from pregnant cows at the time of recheck in experiment 1 were classified as requiring recheck. It is clear that the optimum time to check for pregnancy using this assay is in the 2 -wk period from d 30 to 44 after insemination. A high degree of accuracy is obtained again on d 74 and thereafter.

Relative levels of PAG measured in milk samples were approximately half of the levels measured in plasma and highly correlated $(\mathrm{r}=0.79 ; P<0.001$; Figure 3). This is to be expected, as milk is a filtrate of blood and PAG are relatively large (molecular weight $=40-80,000)$ glycoproteins (Green et al., 2005) associated with the aqueous portion of milk. Essentially the same temporal patterns were obtained in the 2 assays (Figure 2). The earliest time points at which plasma samples from pregnant cows had greater levels of PAG than nonpregnant cows were d 23 and 25 postinsemination. Whereas an increase can be detected at these

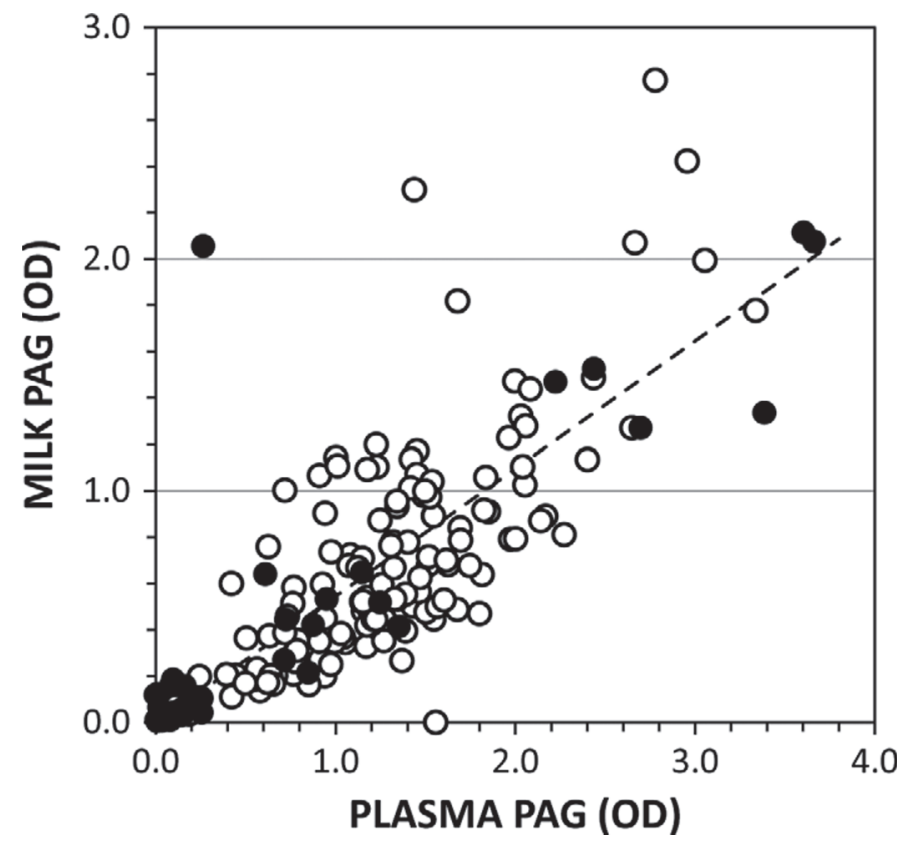

Figure 3. Comparison of relative concentrations of pregnancyassociated glycoproteins (PAG) between plasma and milk in samples collected on d 23 or thereafter from pregnant cows (open circles) and cows experiencing embryonic mortality (solid circles). Correlation coefficient $=0.78(P<0.0001)$. The linear regression equation defining the relationship was milk optical density $(\mathrm{OD})=0.55 \times$ plasma OD -0.01 (adjusted $\mathrm{r}^{2}=0.62, P<0.0001$ ). The regression line is represented by the dashed line in the graph.

times, the levels of PAG do not reach the threshold required to be classified pregnant in plasma until d 30 and 32. Pregnancy detection is $100 \%$ accurate on $\mathrm{d} 30$, $32,37,39$, and 44 . The transient drop in PAG levels is observed in plasma samples as well. Due to differences in the positioning of the threshold values between the 2 assays, many more plasma samples fall in to the range requiring recheck, particularly on d 58,60,65, and 67 . The high degree of accuracy is restored on d 86 and thereafter. In conclusion, the milk-based assay gives essentially the same results as the well-established and validated plasma- and serum-based assay.

The accuracy of the milk-based assay was evaluated using samples collected in experiments $2 \mathrm{a}$ and $2 \mathrm{~b}$ in the same way as in experiment 1 (Table 4). Samples used were from pregnant and nonpregnant cows, $30 \mathrm{~d}$ postinsemination or thereafter. The results were similar to those in experiment 1 . The negative and positive predictive values were 98.8 and $100 \%$, respectively. The sensitivity and specificity were 99.2 and $100 \%$, respectively. Overall accuracy was $99.5 \%(\kappa=0.99)$.

When collected at weekly intervals, the milk-based pregnancy detection assay was also useful in establishing the occurrence of embryonic mortality. As seen in Figure 2, many pregnant animals have a detectable rise 
Table 4. Measurements of accuracy of the pregnancy detection assay in experiments $2 \mathrm{a}$ and $2 \mathrm{~b}^{1}$

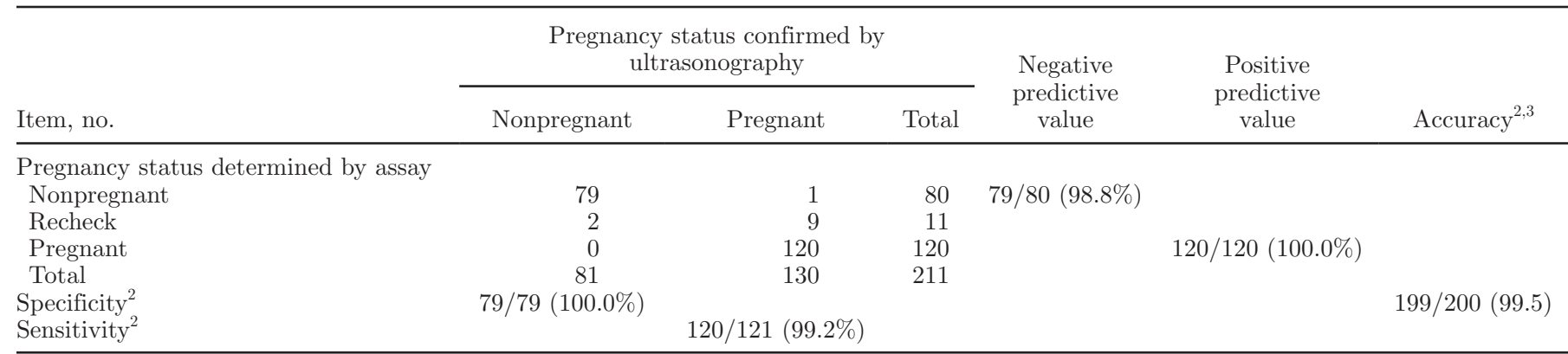

${ }^{1}$ Samples were collected on d 30 to 95 postinsemination. Pregnancy status was confirmed by transrectal ultrasonography.

${ }^{2}$ Estimate does not include samples classified as requiring recheck by the assay.

${ }^{3}$ Kappa (test of agreement between methods) $=0.99$.

in the level of PAG in milk on d 23 or 25 . This is clearly not the case in nonpregnant cows (Figure 4). In these 2 studies, we observed 6 animals whose progesterone concentrations, relative PAG levels, or ultrasonographic imaging suggested that a pregnancy may have been initiated but that the pregnancy was lost during the experimental period. The concentrations of progesterone and relative level of PAG in these animals are shown in Figure 5. Four of these animals were confirmed pregnant by ultrasonography at the first check (cows H493
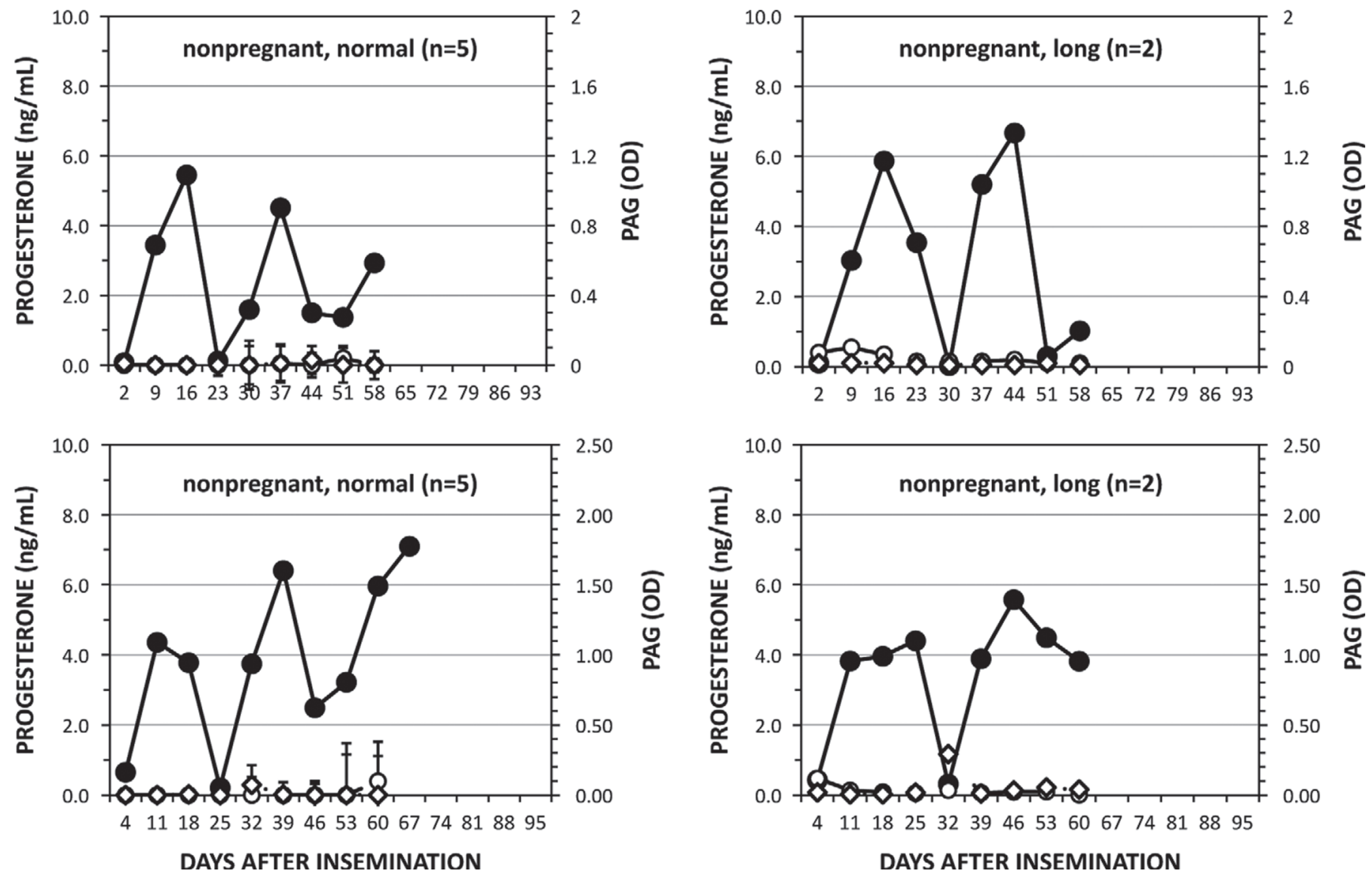

Figure 4. Relative levels of pregnancy-associated glycoproteins (PAG) in milk (open circles) and plasma (open diamonds) and concentrations of progesterone (solid circles) for nonpregnant cows in experiments $2 \mathrm{a}$ (top 2 panels) and $2 \mathrm{~b}$ (bottom 2 panels). Panels on the left are from cows classified as having normal-length estrous cycles (progesterone $<1 \mathrm{ng} / \mathrm{mL}$ on d 23 or 25). Panels on the right are from cows classified as having long estrous cycles (progesterone $<1 \mathrm{ng} / \mathrm{mL}$ on d 30 or 32). Vertical bars on milk and plasma PAG for cows with normal-length estrous cycles indicate SEM. These are included to facilitate comparison to milk and plasma PAG in pregnant cows in Figure 2. 
PREGNANCY DETECTION ASSAY FOR MILK SAMPLES
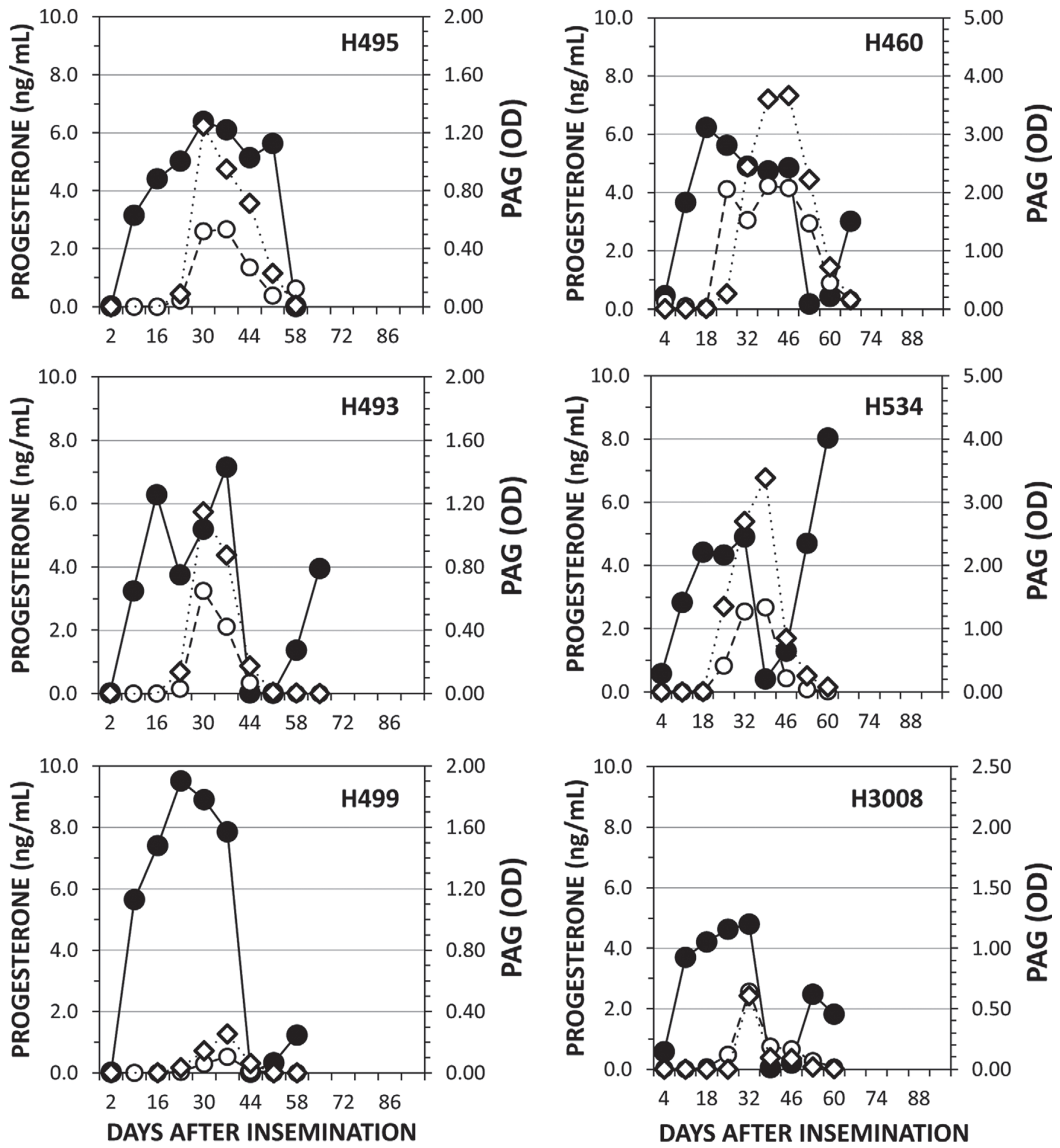

Figure 5. Relative levels of pregnancy-associated glycoproteins (PAG) in milk (open circles) and plasma (open diamonds) and concentrations of progesterone (solid circles) in plasma for cows that experienced embryonic mortality in experiments $2 \mathrm{a}$ and $2 \mathrm{~b}$. Individual cow identification numbers are indicated in the upper right corner of each panel. 
and H495, d 37; cows H460 and H534, d 32), but not at the second. In 2 cows, PAG levels were classified as pregnant on $\mathrm{d} 25$. In the other 2 cows, sampled on $\mathrm{d}$ 23, the level of PAG had increased above typical basal levels, but not high enough to be classified as requiring recheck. On d 30 or 32 , all 4 were classified by the assay as pregnant. The duration of time over which the level of PAG remained elevated was variable. In cow H460, levels remained elevated through d 67 postinsemination. In cow 493, levels fell to basal levels by d 51 . The duration of elevated PAG levels did not appear to have any relationship with the lifespan of the corpus luteum. With a larger number of cows, Thompson et al. (2010) observed that cattle experiencing embryonic loss between d 28 and 60 postinsemination had lower concentrations of PAG in plasma on d 30 than cows that maintained their pregnancy. The limited numbers available in our study preclude this type of analysis; however, 2 of the cows that experienced embryonic loss (H460 and H534) had very high PAG OD levels on d 30, yet lost their pregnancy. Clearly, embryonic mortality is a complex process that is not always associated with a lower relative concentration of PAG using this assay.

Two cows (H499 and H3008) had prolonged luteal phases but were not found pregnant by ultrasonography at the first check. These cows exhibited very transient increases in PAG levels, at or near the requiring recheck threshold. If present, the increase in PAG was very small on d 23 or 25 . The peak occurred on d 32 or 37 postinsemination. A similar pattern of PAG concentrations was observed in the plasma of cows that were assumed to be experiencing embryonic mortality in a previous study (Humblot et al., 1988). As PAG were clearly present, it seems likely that these cows were initially pregnant. Pregnancy-associated glycoproteins are synthesized in binucleate giant cells of the trophoblast (Wooding et al., 2005). They are secreted after migration of these cells across the conceptus-maternal interface in response to fusion of the cells with maternal uterine epithelial cells. Perhaps the structural development of the conceptus was retarded or the conceptus was defective and had already begun to regress. In either case, the conceptus was small and undetectable by ultrasound but still capable of secreting some PAG. When embryonic mortality was induced experimentally, concentrations of PAG fell gradually throughout the 7- to 10-d period following induction (Szenci et al., 2003; Breukelman et al., 2005; Giordano et al., 2012). In all 3 studies, concentrations of PAG at the end of the sampling period had not fallen to the basal concentrations observed during the first 14 $\mathrm{d}$ postinsemination. The half-life of PAG in blood has been estimated to be 7 to $8 \mathrm{~d}$ (Zoli et al., 1992; Kiracofe et al., 1993). Thus, relatively high concentrations of
PAG in the absence of a detectable embryo are most likely the result of residual PAG previously secreted by the now dead embryo. This may prove to be useful to researchers studying various aspects of embryonic mortality. More research is needed to determine if PAG play any active role in maintaining the pregnancy. In the future, it may be possible to quantify PAG in the milk line, as is currently being done with progesterone, offering a very powerful combination of endocrine tools to monitor reproductive status.

In conclusion, the milk-based pregnancy-detection test was accurate. Results compared favorably to the blood-based pregnancy-detection assay that has been used successfully in the field for several years. The assay provides an accurate alternative for dairy farmers who have limited access to a veterinarian or technician skilled in manual or ultrasonographic detection of pregnancy. It also may have some utility as a research tool in studying the biological basis for embryonic mortality.

\section{ACKNOWLEDGMENTS}

The authors thank David Corbin (Corbin Bros. Dairy, Campbellsville, KY) for collection of milk samples for experiment 1 . We are grateful to Joey Clark and the University of Kentucky Coldstream Dairy Farm (Lexington) crew for care of the cows and assistance with sample collection for experiments $2 \mathrm{a}$ and $2 \mathrm{~b}$ and to Susan Hayes (University of Kentucky) for assistance in running the progesterone assays for experiments $2 \mathrm{a}$ and 2b. Michelle Tate and Patrick McCoy (both from University of Kentucky) also assisted with sample collection in experiment 2a. This research was supported in part by the Kentucky Agricultural Experiment Station and is published with the approval of the director (14-07-028).

\section{REFERENCES}

Bello, N. M., J. P. Steibel, and J. R. Pursley. 2006. Optimizing ovulation to first $\mathrm{GnRH}$ improved outcomes to each hormonal injection of Ovsynch in lactating dairy cows. J. Dairy Sci. 89:3413-3424.

Breukelman, S. P., O. Szenci, J.-F. Beckers, H. Kindahl, E. J. H. Mulder, F. H. Jonker, B. van der Weijden, D. Revy, K. Pogany, J. Sulon, I. Némedi, and M. A. M. Taverne. 2005. Ultrasonographic appearance of the conceptus, fetal heart rate and profiles of pregnancy-associated glycoproteins (PAG) and prostaglandin $\mathrm{F}_{2 \alpha}$-metabolite ( $\mathrm{PGF}_{2 \alpha}$-metabolite) after induction of fetal death with aglepristone during early gestation in cattle. Theriogenology 64:917-933.

Gajewski, Z., M. Petrajtis-Golobow, A. Wehrend, N. Melo de Sousa, and J.-F. Beckers. 2014. Comparison of accuracy of pregnancy-associated glycoproteins (PAGs) concentration in blood and milk as methods for early pregnancy diagnosis in cows. Reprod. Domest. Anim. 49(Suppl. 1):18-19.

Giordano, J. O., J. N. Guenther, G. Lopes Jr., and P. M. Fricke. 2012. Changes in serum pregnancy-associated glycoprotein, pregnancyspecific protein $\mathrm{B}$, and progesterone concentrations before and af- 
ter induction of pregnancy loss in lactating dairy cows. J. Dairy Sci. 95:683-697.

Green, J. A., T. Parks, M. P. Avalle, B. P. Telugu, A. L. McLain, A. J. Peterson, W. McMillan, N. Mathialagan, R. R. Hook, S. Xie, and R. M. Roberts. 2005. The establishment of an ELISA for the detection of pregnancy-associated glycoproteins (PAGs) in the serum of pregnant cows and heifers. Theriogenology 63:1481-1503.

Humblot, F., S. Camous, J. Martal, J. Charlery, N. Jeanguyot, M. Thibier, and R. G. Sasser. 1988. Pregnancy specific protein B, progesterone concentrations and embryonic mortality during early pregnancy in dairy cows. J. Reprod. Fertil. 83:215-223.

Kiracofe, G. H., J. M. Wright, R. R. Schalles, C. A. Ruder, S. Parish, and R. G. Sasser. 1993. Pregnancy-specific protein B in serum of postpartum beef cows. J. Anim. Sci. 71:2199-2205.

Leblanc, S. J. 2013. Field evaluation of a pregnancy confirmation test using milk samples in dairy cows. J. Dairy Sci. 96:2345-2348.

Nebel, R. L. 1988. On farm milk progesterone tests. J. Dairy Sci. $71: 1682-1690$

Nebel, R. L., D. L. Altemose, T. W. Munkittrick, D. J. Sprecher, and M. L. McGilliard. 1989. Comparison of eight commercial on-farm milk progesterone tests. Theriogenology 31:753-764.

Patel, O. V., I. Domeki, N. Sasaki, T. Takahashi, M. Hirako, R. G. Sasser, and P. Humblot. 1995. Effect of fetal mass, number and stage of gestation on pregnancy specific protein B concentrations in the bovine. Theriogenology 44:827-833.

Patterson, D. J., J. B. Hall, N. W. Bradley, K. K. Schillo, B. L. Woods, and J. M. Kearnan. 1995. Improved synchrony, conception rate, and fecundity in postpartum suckled beef cows fed melengestrol acetate prior to prostaglandin $\mathrm{F}_{2 \alpha}$. J. Anim. Sci. 73:954-959.

Pursley, J. R., M. O. Mee, and M. C. Wiltbank. 1995. Synchronization of ovulation in dairy cows using $\mathrm{PGF}_{2 \alpha}$ and $\mathrm{GnRH}$. Theriogenology 44:915-923.

Romagnolo, D., and R. L. Nebel. 1993. The accuracy of enzymelinked-immunosorbent-assay and latex agglutination progesterone test for the validation of estrus and early-pregnancy diagnosis in dairy cattle. Theriogenology 39:1121-1128.

SAS. 1985. SAS User's Guide: Statistics. SAS Institute Inc., Cary, NC.
Sasser, R. G., C. A. Ruder, K. A. Ivani, J. A. Butler, and W. C. Hamilton. 1986. Detection of pregnancy by radioimmunoassay of a novel pregnancy-specific protein in serum of cows and a profile of serum concentrations during gestation. Biol. Reprod. 35:936-942.

Silva, E., R. A. Sterry, D. Kolb, N. Mathialagan, M. F. McGrath, J. M. Ballam, and P. Fricke. 2007. Accuracy of a pregnancy-associated glycoprotein ELISA to determine pregnancy status of lactating dairy cows twenty-seven days after timed artificial insemination. J. Dairy Sci. 90:4612-4622.

Szenci, O., J.-F. Beckers, J. Sulon, M. M. Bevers, L. Borzsonyi, L. Fodor, F. Kovacs, and M. A. Taverne. 2003. Effect of induction of late embryonic mortality on plasma profiles of pregnancy-associated glycoprotein 1 in heifers. Vet. J. 165:307-313.

Telugu, B. P. V. L., A. M. Walker, and J. A. Green. 2009. Characterization of the bovine pregnancy-associated glycoprotein gene family-Analysis of gene sequences, regulatory regions within the promoter and expression of selected genes. BMC Genomics 10:185.

Thompson, I. M., R. L. A. Cerri, I. H. Kim, J. A. Green, J. E. P. Santos, and W. W. Thatcher. 2010. Effects of resynchronization programs on pregnancy per artificial insemination, progesterone, and pregnancy-associated glycoproteins in plasma of lactating dairy cows. J. Dairy Sci. 93:4006-4018.

Watson, P. F., and A. Petrie. 2010. Method agreement analysis: A review of correct methodology. Theriogenology 73:1167-1179.

Wiltbank, M. C., and J. R. Pursley. 2014. The cow as an induced ovulator: Timed AI after synchronization of ovulation. Theriogenology 81:170-185.

Wooding, F. B., R. M. Roberts, and J. A. Green. 2005. Light and electron microscopic immunocytochemical studies of the distribution of pregnancy-associated glycoproteins (PAGs) throughout pregnancy in the cow: Possible functional implications. Placenta $26: 807-827$.

Zoli, A. P., L. A. Guilbault, P. Delahaut, W. B. Ortiz, and J.-F. Beckers. 1992. Radioimmunoassay of a pregnancy associated glycoprotein in serum: Its application for pregnancy diagnosis. Biol. Reprod. 46:83-92. 